\title{
Third-Party Logistics Service Mode for CPG Supply Chain Based on Cloud Platform
}

\author{
Ling Wei, Xinpen Guo and Yang Li \\ School of Management, Harbin University of Science and Technology, Hei \\ Longjiang Harbin150040, China \\ weiling@hrbust.edu.cn
}

\begin{abstract}
In supply chain management for Consumer Package Goods $(C P G)$, information on traditional third-party logistics is not synchronized on business and logistics process. Paper presents a third-party logistics information service model based on the cloud platform. This is a cross-enterprise integration model, which eliminate islands of information between enterprises. Because the model not only pass the data, but also synchronize the operation process between logistics and commerce, it improve the CPG supply chain operation efficiency, and generate social and economic benefits.
\end{abstract}

Keywords: CPG, Third-party logistics, Information service, Cloud platform, Integration

\section{Introduction}

CPG is social product used to meet the daily life and ensure social reproduction. Because of great variety, large consumption and frequent use, CPG supply chain logistics need to have more stringent requirements. The process of CPG supply chain from raw materials procurement to products retail is relatively longer, the logistics cost is relatively high. In order to meet the needs of the market, the logistics activity rhythm should be fast and response to customer demand.How to reduce logistics cost and improve the response speed from longer supply chain, this puts forward the requirements for the corresponding logistics service mode. The supply chain logistics service of CPG is related to our country's basic economy and people's daily life.Due to the rapid development of the logistics industry in recent years, the third-party logistics service gradually deep into all aspects of CPG supply chain, including raw materials procurement, product processing and product retail. The development of the CPG industry can not be separated from the development of the logistics industry, efficient logistics service mode is the basic guarantee to develop the CPG industry. The independence between the logistics management information system on traditional third-party logistics mode, resulting in out of sync between the business flow, information flow and logistics, and directly influencing the market demand response speed, operating cost and management benefit [1]. How to improve the CPG supply chain overall operating efficiency and eliminate bottlenecks caused by the traditional third-party logistics service. As cloud computing becomes more mature, some application system transfer to the cloud platform, this powerful virtual resources pool achieve information sharing, business collaboration, unified dispatch and operation [2]. In order to eliminate information islands, improve transparency and response of CPG supply chain logistics, this paper presents a third-party logistics service based on cloud platform for CPG supply chain. 


\section{Related Concepts}

\subsection{Third-Party Logistics Service and Consumer Package Goods}

Enterprises and professional logistics service corporation signed a contract, so that logistics service corporation to do the logistics activities, which is the third party logistics.Enterprise not only to focus on the main business, but also to monitor the implementation of logistics service corporation logistics activities.Enterprises need to maintain close contact with the logistics service corporation in the course of logistics activities [3]. The third-party logistics is the embodiment of the social division of labor,provide professional services to the enterprises through its professional logistics service advantages.The modern third-party logistics is based on modern electronic information technology, to realize the comprehensive logistics service to customers [4].Third-party logistics services to help companies focus on the main industry, save investment, reduce inventory and enhance corporate image. Third party-logistics services in different industries have different connotations, especially in the CPG industry.The third-party logistics service throughout the CPG supply chain is the basic guarantee for the development of the CPG industry.

\subsection{Third-Party Logistics Services and Cloud Computing}

The basic principle of cloud computing is to provide the user with the ability to calculate and storage through the construction of a large number of distributed computers. The rapid development of cloud computing has brought changes to all walks of life, including the logistics industry.Cloud computing using the network to integrate the computing resources into a virtual resource pool, then to provide computing and storage to the user through the network. Cloud computing has brought profound changes to the operation and management of the logistics industry [5]. It is one of the important contents of the third party logistics service mode innovation to use new technology, new application and other means to increase the added value of logistics services [6]. With the wide use of cloud computing, logistics enterprise and CPG enterprise move their information system to the cloud computing platform. This is the key to realize the information sharing, business collaboration and process consistency in logistics management [7].

\section{Traditional Third-Party Logistics Service}

\subsection{Simple Information Docking Stage}

There is a forward flow of information between enterprises, but the information is not timely feedback. Third-party logistics information system between enterprises is independent, only transfer business data, without the each specific operation. Although integrated logistics service up, but the commerce, logistics and information flow is not synchronous. Simple information docking cause a inconsistency between information flow and logistics processes, the backlog of inventory, procurement cycle extended, material condition on the road can't grasp the first time etc, also the information docking process is difficult, resulting in logistic flow separate as Figure 1. 


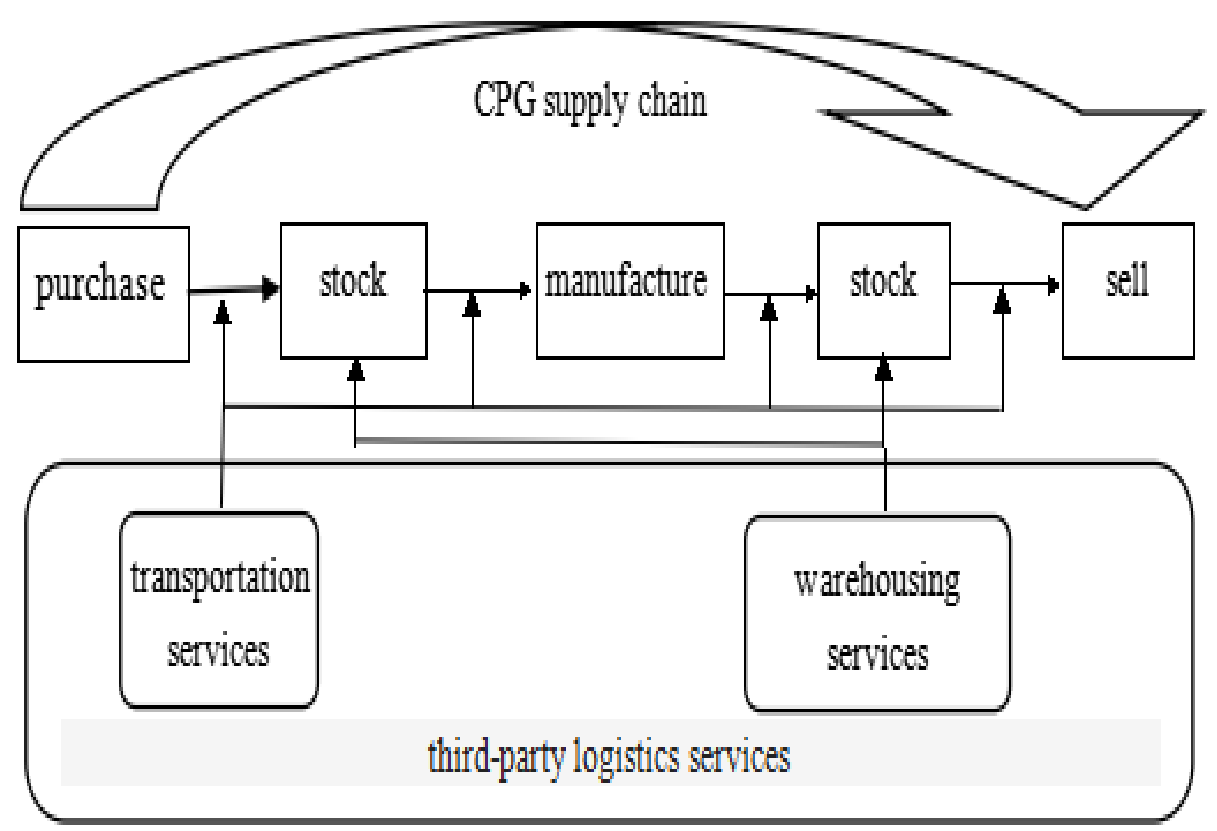

Figure 1. Simple Data Docking Structure

\subsection{EDI information Docking Stage}

EDI is a international standard format for interchange of trade data by computer network, which usually come from enterprises to enterprises, enterprises to the relevant departments. These business data including trade, transportation, insurance, banking and customs. The third-party logistics enterprises in the connection part in the whole supply chain, which need to exchange data from logistics demand enterprise, so the EDI is more common application in the third-party logistics [8]. In this mode, the specific process isolation between supply chain enterprise, has seriously hindered the overall efficiency of the supply chain as Figure 2. The main problems are as follows:

a) The cooperative communication is inter enterprise, and operation process is also cross platform, resulting in the information could not be shared.

b) Information feedback delay and error, then the functional departments can not to grasp the information of inventory, logistics processing condition, resulting in reducing order fulfillment rate of enterprises and not providing a guarantee for the main business.

c) Because the transmission of information is not timely, resulting in related businesses rush. Enterprises abnormal activity, such as emergency orders, returns, etc, is difficult to meet customer requirements for service levels and flexibility.

d) Orders critical information delivery is not timely and the logistics business operations delayed, resulting in third-party logistics services efficiency and cost advantages can not be fully realized. 


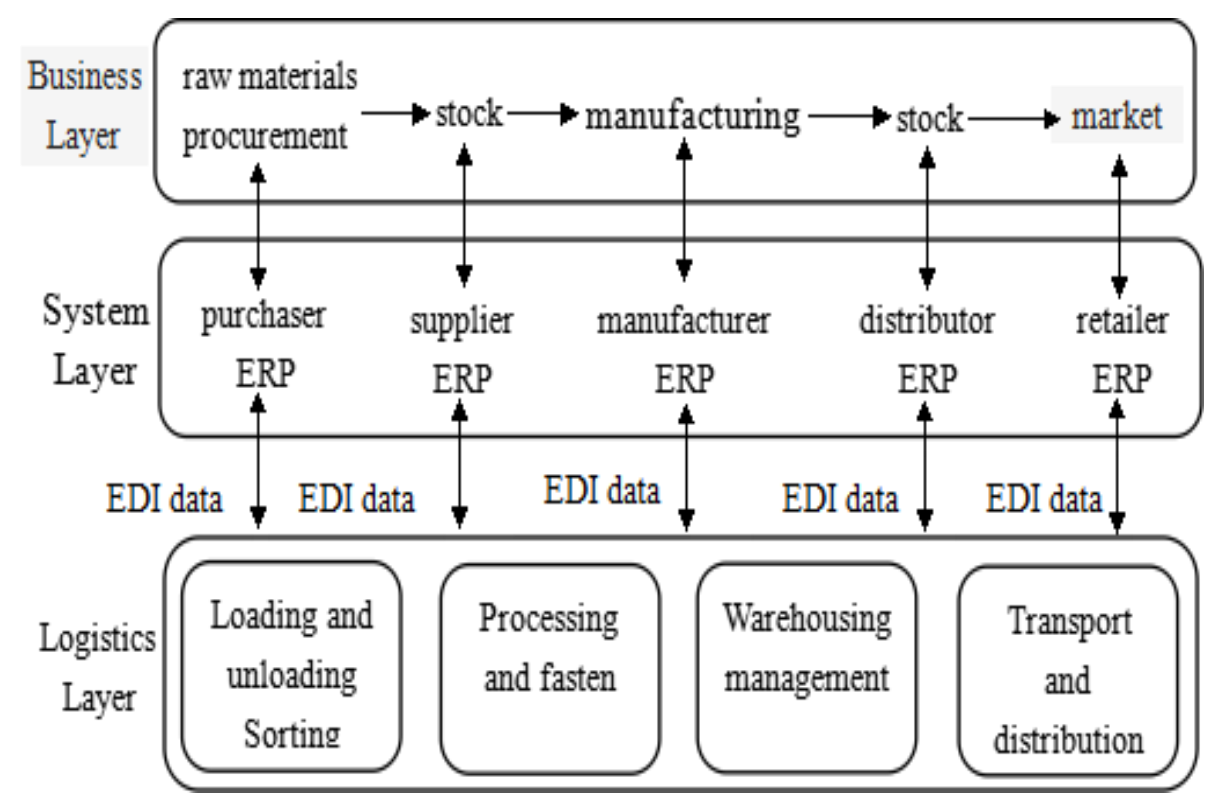

Figure 2. DEI Information Docking

In order to solve the problem of third-party logistics services in the traditional supply chain, the following will introduce a third-party logistics service mode based on cloud platform, this mode complete data docking on process level.

\section{Third-Party Logistics Service Mode Based on Cloud Platform}

\subsection{Cloud Platform Third-Party Logistics Service Structure}

With the continuous improvement of the third-party logistics services, logistics activities in procurement, manufacturing and sales gradually outsourcing to the third party logistics.The third-party logistics has the mission of integrated management of internal and external logistics. The third-party logistics needs to integrate the ERP system of other enterprises in the supply chain, and then make the system in the same information platform to achieve full communication and coordination.With the wide use of cloud computing, logistics enterprise and CPG enterprise move their information system to the cloud computing platform. This is the key to realize the information sharing, business collaboration and process consistency in logistics management. In the traditional third party logistics service mode, the information system of supply chain enterprise is independent operation in the enterprise, and lack of information communication between enterprise system. In the third-party logistics service mode base on cloud platform, CPG supply chain and logistics enterprise can complete related work and realize seamless connection of supply chain logistics information according to the predetermined limits of authority and procedure. The users on the platform can not only maintain the relative independence but also can achieve the division of labor cooperation, including the cooperation between the enterprise and the enterprise. Such collaboration connecting the various links in the logistics supply chain, making the CPG supply chain logistics business breakthrough time and space constraints. The third-party logistics service mode base on cloud computing architecture realize information sharing, cross enterprise cooperation, logistics resource integration, logistics process reengineering and logistics information analysis and decision. This new model can integrate the vehicle transportation management system and logistics and supply chain consulting services to provide smooth and integrated logistics information service for the whole supply chain enterprise, as shown in Figure 3. 


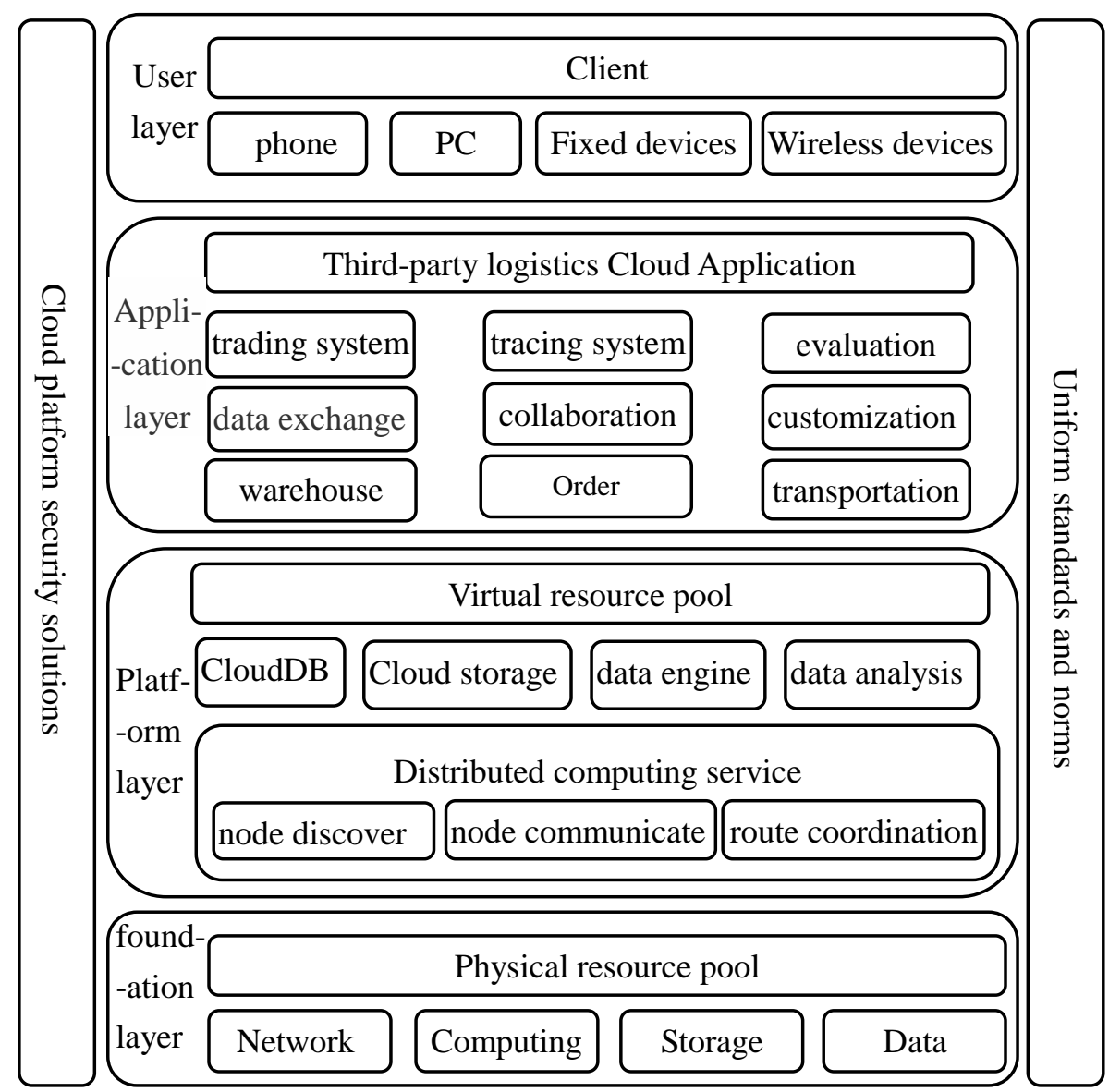

Figure 3. CPG Third-Party Cloud Platform

a) Infrastructure layer. This layer provides computing, storage and network resources. Due to the intensive management, it is not only convenient for the application of flexible deployment and management, but also provides the guarantee for the continuity of the platform business.

b) Platform layer. This layer provides all the tools and API for building and deploying cloud logistics application, which Allows users to deploy and run applications on the data processing platform. Distributed architecture can improve the massive data analysis, storage, and retrieval efficiency, and give full play to the potential of computing, storage and network resources.

c) Application layer. This layer provide cloud application. logistics trading system is an electronic trading system, is the rapid trading platform between the third party logistics demand side and provider.Logistics customization system is for enterprises or personal service who have a personalized logistics services needs. Traceability security system can provide traceability of the goods, while providing goods authenticity query function. In the service evaluation system, the third party-logistics service users can evaluate the quality of logistics services, then provide a reference to choose good quality logistics services. In addition, the platform also has the storage management system, data exchange system, business cooperation system, order management system, transportation management system, etc. The platform is a modular, plug-in, open cloud application platform, which can support the third party logistics applications integrated into the platform.

d)User layer. user connect to the cloud platform through the Internet and use the services provided by application layer. Users include the CPG supply chain enterprises and the 
third-party logistics enterprises. Mobile terminals such as mobile phones, laptops and PC help users master and operate real-time information. terminal distribution in plant, logistics center, etc, to facilitate the delivery and receiving of goods information. Fixed terminal distribution in plant, logistics center, etc, to facilitate the delivery and receiving of goods information.

\subsection{Integrated Process Analysis of Third-Party Logistics in Cloud Platform}

Logistics enterprises and supply chain enterprise need to establish overall logistics process cross enterprise with the help of the platform. The core of the third-party logistics cloud platform including inventory management, order processing and logistics flow visualization, which communicates the logistics process of the supply chain, and makes the integration of the whole operation process as shown in Figure 4.

Cloud platform integrates the logistics data, information process and operation process, not only to improve the transmission speed of the data in each enterprise, but also connected the entire fast consumer goods supply chain enterprise logistics process. In addition, the cloud platform also addresses the process of independence between enterprises, and improve the service efficiency overall supply chain logistics. In the traditional logistics service mode, the information is transmitted from the start of the supply chain to the end of the supply chain. Because of the supply chain is longer than other industries, and the number of enterprises in the chain is relatively large, so the more information transmission time.The traditional logistics service mode, which not only brings delay of the information, but also may reduce the accuracy of the information. The third-party logistics cloud platform provides a common platform for interaction to belong to the different aspects of the members.The upstream enterprises and downstream enterprises can acquire logistics information at the same time, avoiding the Bullwhip Effect. Logistics information nearly simultaneously in the supply chain, reduce the information transmission time and supply chain inventory, and improve the CPG supply chain reaction ability.

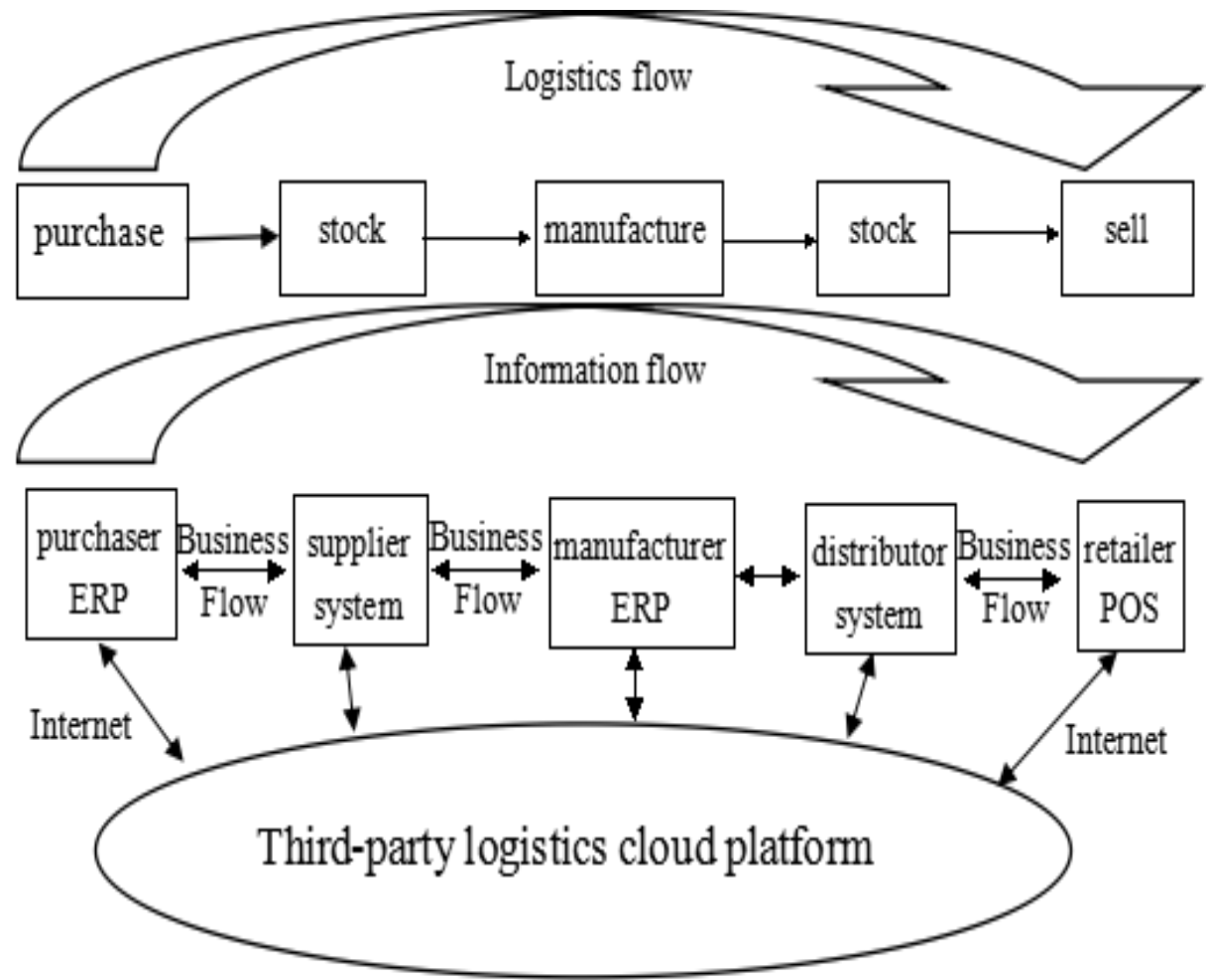

Figure 4. The Third-Party Logistics Cloud Platform Structure 


\subsection{Guarantee for the Implementation of the Integration Process.}

a) Real information sharing. In the design of the integrated process, the logistics enterprise and CPG enterprises must establish a strategic partnership, which is the only way to break through the information self protection, and to achieve full sharing of information. In order to achieve the overall process optimization, logistics enterprises and CPG supply chain enterprises need to reach a consensus.

b) Familiar with the integration of operation. In the initial stage, the main problems are easy to mistake, do not match between enterprises. Enterprises in the supply chain must maintain close consultation mechanism. The integration process involves more than one enterprise, must handle each phase of the data, to ensure that the requirements of the operation of accurate specifications.

c) Establish assessment system. In the early days of integration, we should use the KPI assessment system to find and solve problems early. KPI is conducive to a clear stage objectives, to achieve logistics integration.

\section{Economic Effects and Social Effects}

\subsection{Economic Effects}

This model simplifies the process, reduces the amount of employment, and save the cost of human resource. In a certain storage resources, the platform has realized the synchronous between operation process and information system, enhance the processing capacity of logistics order, and improves the storage resource utilization. Under limited transportation resources, cloud platform reasonably arrange the transportation resources, improve the utilization rate of transport resources. Analysis from the Transaction Cost Theory, cloud platform reduces friction and transaction cost. According to the statistics of the statistical information network, under the condition of the same traffic, the logistics mode of the cloud platform is reduced by more than $50 \%$ of the business processing time, as shown in Figure 5.

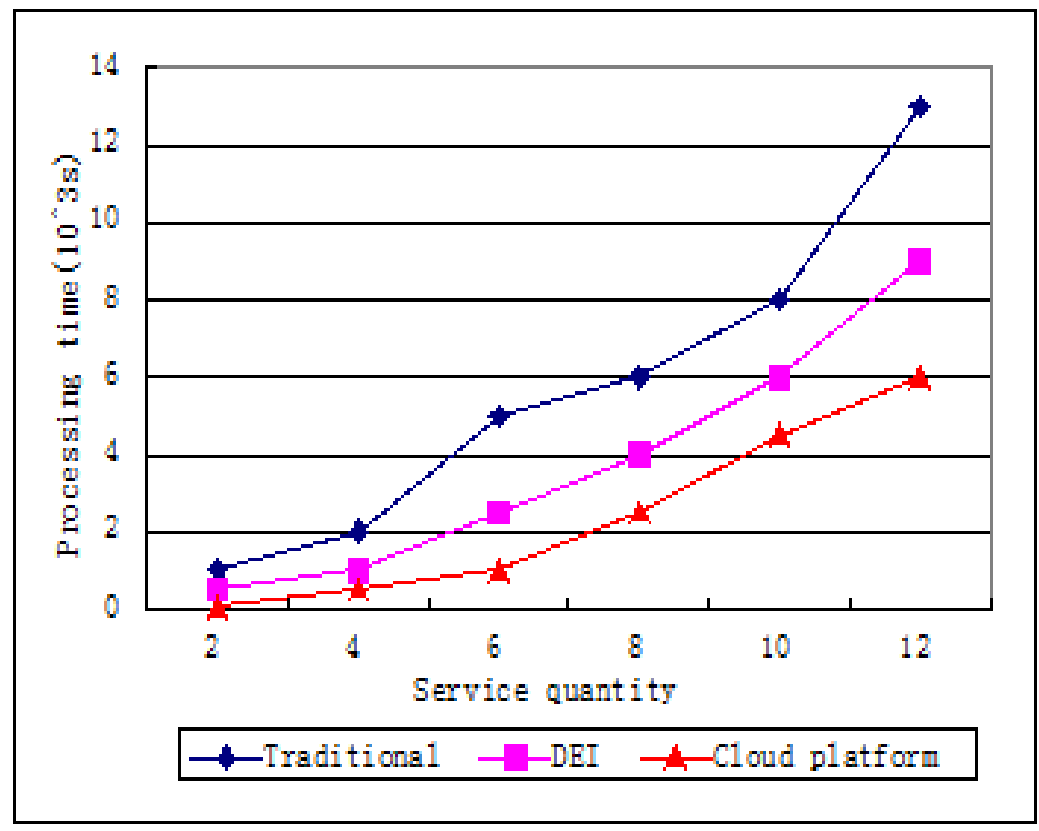

Figure 5. Processing Capacity of Information 


\subsection{Social Effects}

Cloud platform for CPG logistics supply chain process docking provides overall solutions and framework, realizing seamless docking between manufacturing, distribution industry and the third-party logistics service. Unified information platform is conducive to the establishment of logistics standards throughout the CPG supply chain, including acquisition, transmission, processing and controls.Under the condition of equal volume of business, the cost reduction of $30 \%$, the amount of labor is reduced by $8 \%$, the usage of resources is reduced by 10\%, as shown in Figure 6.

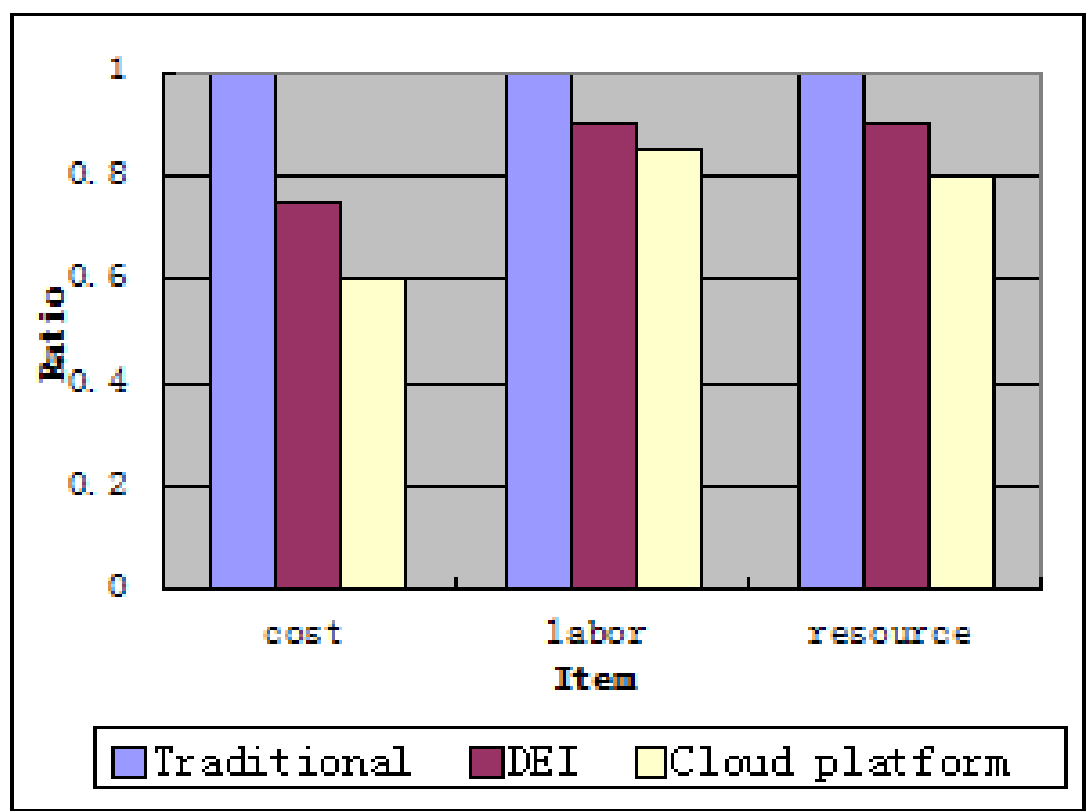

Figure 6. Cost, Labor and Resource in Three Information Service Modes

\section{Conclusion}

This paper presents third-party logistics service model based on cloud platform, which solves the problem of the supply chain process segmentation. It can directly create economic effect and social effect to the enterprise, improve the third party logistics service level of CPG manufacturing industry and distribution industry etc Content of the next step is how to build a cloud platform more in line with the characteristics of CPG industry characteristics, enterprise information systems is how to migration to the cloud platform.

\section{Acknowledgment}

The Research supported by the National Natural Science Foundation of China(No. 71301036, No. 71171069).

\section{References}

[1] O. Mortensen and O. W. Lemoine, "Integration between manufacturers and third party logistics providers", International Journal of Operations \& Production Management,vol. 28, no. 2, (2008), pp. 125-128.

[2] L. Zhang, B. Fan and Weiping Zhen, "Research on the application of system migration method on cloud platform", Computer science, vol. 40, no.6, (2013), pp. 271-273.

[3] Y. Cheng, "Third-party logistics", (Second Edition). Tsinghua University press, (2013), pp. 3-10.

[4] J. You and S. Lao, "Supply chain coordination of third party logistics service quality", Journal of Tongji University, (2012), vol. 40, no. 9, pp. 14-22. 
[5] "Virtual and cloud computing group", Cloud computing technology and Implementation. Beijing:: Electronic Industry Press, (2011), pp. 165-167.

[6] D J. Flint, "Logistics innovation: A customer value-oriented social process", Journal of Business Logistics, , vol. 26, no. 1, (2005), pp. 113-147.

[7] K. Chen and W. Zhen, "Cloud computing system instances and current research", Journal of software, vol. 20, no. 5, (2009), pp. 1337-1348.

[8] H. Yang and J. Chen, "Platform design for electronic data interchange for Logistics", China circulation economy, vol. 9, no. 4, (2012), pp. 34-35. 
International Journal of $u-$ and e- Service, Science and Technology Vol.9, No. 5 (2016) 